\title{
PREDICTIVE VALUE OF LABORATORY PERFORMANCE TO INTERNSHIP COMPETENCIES
}

\author{
Rosyl Arlene P. Alfuente, Ralph Alvin R. Canoy, \& Roselyn Joy G. Dimasuay \\ Department of Psychology, World Citi Colleges-Quezon City (Philippines)
}

\begin{abstract}
As the subject courses Experimental Psychology and Psychological Assessment are focal contributors in the theoretical aspect of the students' performance in the three internship settings in Psychology it is of vital importance to assess the effectiveness of the Psychology Laboratory where the aforementioned courses are being held. The study served as an efficacy evaluation of the department's laboratory. It established the predictive value of the students' laboratory performance on their internship performance. The main source of data came primarily from all the third year Psychology Students who are taking Psychological Assessment, and Experimental Psychology (Internship) and are enrolled for the Second Semester, Academic Year 2018-2019 at World Citi Colleges, Quezon City. Purposive sampling was used in the conduct of study. It involved collection, analysis, and an interpretation of quantitative data extracted from the grade repository of the institution. The data were taken from the grades in Psychological Assessment and Experimental Psychology as well as grades in Practicum in Psychology. The data were subjected to Multiple Regression to test whether the Experimental Psychology grades and the Psychological Assessment grades have the significant predictive value relevant to the Practicum Grades of the psychology students. Findings showed that the Experimental Psychology grades and Psychological Assessment were not statistically significant when it comes to predicting the practicum grades of the students, $F(2,21)=2.630, p>0.05, R^{2}=.448$. Neither of the regressors was statistically significant as well when it comes to predicting the practicum grades of the students. This means that the regressors used were not a good fit for the prediction model intended to measure the practicum grades of the students. It can therefore be concluded that the Experimental Psychology and Psychological Assessment grades were not sufficient to forecast the outcome of the Practicum grades of the psychology students in educational, clinical, and industrial settings.
\end{abstract}

Keywords: Experimental psychology, psychological assessment, practicum, predictor, multiple regression.

\section{Introduction}

Predictive values are used to elucidate the results of a test by studying the exact grouping of individuals based the test. This measure is significant because whether a person is really a case or non-case is challenging to determine, however, what is established is a positive or negative result of a test. The courses which are Experimental Psychology and Psychological Assessment are focal contributors in the theoretical aspect of the students' performance in the three internship settings in Psychology specifically, Clinical, Industrial/Organizational, and Educational. The predictive value of the grades acquired by the students have been examined vis- a vis their grades in the three settings of Practicum/Internship. In so doing, it is therefore imperative to assess the effectiveness of the Psychology Laboratory where the aforesaid courses are being held.

This study focused on how laboratory-assisted academic courses impact on the internship competencies of students in the areas of clinical psychology, industrial-organizational psychology and educational psychology. The desired outcome for the professional curriculum specifies that the department's laboratory should enable students to practice their skills and demonstrate their exit competencies, hence an investigation on the link between laboratory performance and internship performance of students was conducted. The grades of the WCC-QC students Batch 2018 in Psychological Assessment and Experimental Psychology was used to operationally define laboratory performance since both subjects involved extensive use of the psychology laboratory. 
Practicum/Internship Competence

The concept of competence has become the driving force in the education and training of professional psychologists. In fact, competence has evolved into increasingly sophisticated forms, now perhaps best represented by the cube model, which integrates foundational, functional, and developmental variables into professional training. One component of professional training is scientific knowledge, and it is argued that knowledge competence should occur before a student is certified as internship ready (Burke \& Prieto, 2019).

Most psychology programs require students to complete a practicum or internship to prepare them to work with real patients upon graduation. Supervised, hands-on experiences allow psychology students to better serve their patients and help them to be more successful early on. Internship also benefit their careers by providing them with a network with current professionals who may offer a job upon graduation since most employers offering internships do so with the intention of hiring the intern. Internships offer practical experience for psychology students that help them learn the ins and outs of working in the field, including what it's like to apply theories they learn in class to real people in crisis (psychology.org, 2020)

Not only do psychologists need to understand theory, diagnosis criteria, and treatment options, but they must also know how to build trusting relationships with each client. Because professional interpersonal skills are difficult to teach in a classroom setting, students are given the opportunity to hone them in internships and practicums which help to smooth the transition from school work to a professional role.

This study recognizes the importance of internship and would like to assess how the school resources can more effectively prepare the students for this endeavor. Specifically, this research aimed to find out whether specific laboratory-assisted academic subjects effectively prepare undergraduate psychology students for their internship performance and then, recommend ways on how to improve this connection.

Laboratory Performance

The first experimental psychology laboratory was opened by Wilhelm Wundt at the University of Leipzig in 1879. In the nearly 150 years since, psychologists have been researching human behavior in these controlled settings with great success, garnering much insight into human behavior. But beyond "studying human behavior," psychology is a widely varied field, so depending on the research under study, psychology labs might have different looks (Online Psychology, 2020). For example, research on cognition and brain functioning may have a psychology lab equipped with a functional MRI machine that allows psychological researchers to measure and record a subject's brain activities. On the other side of the spectrum may be a psychology lab built to simply observe what the subject or subjects are doing such as those set up with a two-way mirror to observe the playmaking activities of toddlers in a social setting. Many labs have small interview rooms in which a researcher can meet with a subject in a one-on-one setting for things like interviews or for administering a questionnaire or a test of some kind, like an IQ test. There are even virtual psychology labs today where psychology students can engage in learning about classic psychology research, see how to design and carry out experiments, and learn about the science of investigation.

This study underlines how the laboratory for psychology students is an essential part of the curriculum to provide training in the competencies they need for internship and future career performance. In a study by Heesacker and Elimelech (2015), it was emphasized that the undergraduate laboratory training can be a valuable method of enhancing science-practice integration. It was proven that students with extensive science-practice integration experience at the undergraduate level become better thinkers and more careful consumers of information who are able to compete effectively for coveted positions in applied psychology and applied psychological science training programs. Laboratory training emphasis should be on strengthening the students scientifically, on helping them rediscover their own creative intellectual abilities and intrinsic motivations for conducting science, and on teaching them empirically supported methods to enhance their success in achieving their most-valued objectives and goals (Heesacker \& Elimelech, 2015).

In this study, the role of the laboratory is highlighted in the correlation of students' grades in laboratory-assisted subjects with their internship performance ratings in the clinical, educational and industrial settings. 


\section{Methods}

\subsection{Research design}

The quantitative-correlational research design was used to statistically measure the strength of the relationships between the variables "laboratory performance" and "internship competency".

Laboratory performance was measured through the students' numerical grades in laboratory- assisted academic subjects namely Experimental Psychology and Psychological Assessment, while Internship Competency was measured by the students' internship ratings earned outside school, in the Clinical, Industrial and Educational settings.

\subsection{Population and sampling}

The researchers targeted sample representative of only the psychology students who took the specified academic subjects required. Purposive Sampling was used. This sampling technique is a non- probability technique that involves the conscious selection by the researcher of certain people to include in a study. Participants are selected because they have particular characteristics that are of interest to the researchers.

\subsection{Respondents of the study}

The participants of the study are the third year Psychology students of World Citi Colleges, Quezon Citi Campus, Batch 2018, who took Experimental Psychology, Psychological Assessment and Practicum in Psychology (Internship).

\subsection{Research instrument}

The researchers used the grades of the students on the two psychology laboratory courses and the practicum ratings. Rubrics were used to measure the competencies of the students.

\subsection{Data analysis}

With the general intention to improve the school undergraduate psychology laboratory, this research aimed to find out whether laboratory use effectively and significantly prepared students for graduate exit competencies

The descriptions were analyzed using the descriptive statistics of frequency, weighted mean and percentage to describe the predictive value of the laboratory performances of the students.

To test for the correlation of the laboratory performances of the students on internship competencies Multiple Regression Analysis was used wherein adjusted $\mathrm{R}^{2}$ was determined. Inasmuch as the criteria of having two independent variables as the regressor and one dependent variable for the regress were met, among other criteria, this statistical method was then considered.

\section{Results and discussion}

Based on the analysis made, it was found out that Psychological Assessment course is the most suitable indicator of students' performance during the Practicum/Internship. This is due to the usage of the Psychology laboratory which familiarized students with the various assessment tools that psychologists use to measure and evaluate as well as observe behavior. It accurately trained students to gauge behavior significantly and arrive at a more realistic diagnosis and guide treatment.

The findings indicated that the Experimental Psychology grades and Psychological Assessment were not statistically significant when it comes to predicting the practicum/internship grades of the students, $F(2,21)=2.630, p>0.05, R^{2}=.448$. Neither of the regressors was statistically significant as well when it comes to predicting the practicum grades of the students. This means that the regressors used were not a good fit for the prediction model intended to measure the practicum grades of the students. It can therefore be concluded that the Experimental Psychology and Psychological Assessment grades were not sufficient to forecast the outcome of the Practicum grades of the psychology students.

A psychology laboratory is used for teaching, consultancy and research activities. The psychology laboratories are purposively built rooms that allow psychology students to carry out cognitive and psycho-physiological investigations. The lab usually includes a covert observation room and specified spaces for interview and audiovisual functions. Collecting a wide range of data using laboratory resources give students the opportunity to enhance their psychological methods and analysis as well as experience complex psychological research. 


\section{Recommendation}

Based on this study, there is an emphatic need for the enhancement of the WCC psychology laboratory to provide effective preparation for the undergrad students' professional competencies. Hence, the following recommendations are strongly suggested.

1. A more spacious area should be provided to locate specified adjacent spaces (cubicles) for observation, experiments, testing, group work and related experiential learning.

2. Acquisition and provision for additional laboratory instruments such as computers with data analysis applications and other pertinent psychological tools.

3. Additional psychological testing materials such as cognitive, psychosocial, behavioral and projective assessment tools should be made available for hands-on training and practice.

4. A review and update of the laboratory-assisted academic subject's syllabi content and pedagogy in view of their relevance to the evolved needs and demands of the industry should be conducted.

5. Revise the practicum/internship rating criteria to align with the updated professional competencies required from the students should be considered.

6. Collaborative communication and consultation with the practicum/internship supervisors should be implemented to ensure that objectives are aligned and satisfied.

\section{References}

Bernardo, Alla B.I. (2018) Fo in the Development of formative Assessment that Could Help Improve Student Learning Outcomes in Philippine Schools. Philippine and Global Perspectives on Educational Assessment Vol 1. p. 10

Burke, K. S., \& Prieto, L. R. (2019). High-quality research training environments and undergraduate psychology students. Scholarship of Teaching and Learning in Psychology, 5(3), 223-235. https://doi.org/10.1037/st10000156

Charles S. (Charles Samuel) Myers. A Text-Book of Experimental Psychology (E-Book). (2017) New York: Longmans, Green

Ciccarelli, Sandra K and J. Noland White. Psychology $4^{\text {th }}$ Ed (2015). Singapore: Perason Education South Asia Pte Ltd. ISBN 978-981-4648-50-9

David, Adonis P. and Carlo Magno (2018) Perspective on Educational Assessment: An Introduction. Philippine and Global Perspectives on Educational Assessment Vol 1. p. 3

Heesacker, M., Higley, B. P., \& Elimelech, N. T. (2015). The undergraduate research laboratory as a method of enhancing science-practice integration. Counselling Psychology Quarterly, 28(3), 264-285. https://doi.org/10.1080/09515070.2015.1041454

$\begin{array}{lllll}\text { Internships and Practicums retrieved March } 12,2020 \text { from } & \text { and }\end{array}$ https://www.psychology.org/resources/internships-and-practicums/\#what-to-expect-from-yourpsychology-internship-or-practicum

Rathus, Spencer A. Psychology (2017). Quezon City: C\&E Publishing, Inc. ISBN 978-971-98-0702-5

Robert Woodsworth, Harold Schlosberg. Experimental Psychology (E-Book). New York

Ward, Maximus. Psychology: An Introduction (2017). USA: Larsen \& Keller Education. ISBN 978-1-63549-587-4

What happens in a Psychology Laboratory retrieved March 12, 2020 from https://www.onlinepsychology-degrees.org/study/psychology-laboratory/. 